\title{
PEMANFAATAN QR-CODE SEGABAI MEDIA PROMOSI TOKO
}

\author{
Joseph Dedy Irawan ${ }^{1}$, Emmalia Adriantantri ${ }^{2}$ \\ 1) Teknik Informatika, Institut Teknologi Nasional Malang \\ 2) Teknik Industri, Institut Teknologi Nasional Malang \\ Joseph@lecturer.itn.ac.id
}

\begin{abstract}
ABSTRAK
QR-Code (Quick Response Code) merupakan pengembangan dari Bar-Code yang dulunya merupakan kode saru dimensi menjadi kode dua dimensi dengan kemampuan menyimpan data lebih besar dibandingkan dengan BarCode, dengan menggunakan QR-Code data yang bisa disimpan dapat berupa kode angka, huruf, binary serta huruf kanji, kode ini sudah diterapkan untuk berbagai bidang. Salah satu penggunaan QR-Code adalah sebagai media untuk melakukan promosi bagi toko, karena dengan menggunakan kode ini dan dengan bantuan internet maka akan terbentuk suatu sistem promosi dengan biaya burah tetapi dapat mencakup area yang sangat luas.

Media promosi ini dilakukan dengan cara mempersiapkan data-data barang atau produk yang dijual di toko, kegiatan promosi seperti diskon dan promo yang akan dilakukan toko. Dari data tersebut dimasukkan ke dalam database, kemudian tautan (hyperlink) dari data promosi tersebut disimpan dalam bentuk QR-Code, pelanggan dengan bantuan kamera handphone dapat melakukan scanning dari QR-Code yang diinginkan, dan dengan memasang aplikasi dalam handphone pelanggan maka kode tersebut akan dikirim ke server dan pelanggan akan dikirim informasi promosi yang dilakukan oleh toko, proses ini akan mempermudah pelanggan mencari produk yang diinginkan karena tidak perlu melakukan proses pencarian dari internet, tetapi cukup melakukan scanning dari QR-Code.
\end{abstract}

Keyword : QR-Code, Promosi Toko, pemasaran melalui internet

\section{PENDAHULUAN}

Teknologi dalam bidang informasi sudah banyak mengalami kemajuan tiap tahunnya. Mulai dari informasi yang langsung bisa dibaca seperti berita di internet, koran majalah dan masih banyak lagi, ada pula informasi yang harus diolah terlebih dahulu seperti Bar-Code, QR-Code, enkripsi data dan masih banyak lagi. Teknologi informasi ini dapat dimanfaatkan untuk memberi kenyamanan dalam bidang bisnis seperti ecommerce yang terdapat di dalam toko sebagi media promosi.

Selama ini dalam sistem penjualan yang sudah sangat umum dimanfatkan oleh toko kecil bahkan toko besar adalah pemanfaatan Bar-Code sebagai ID dari suatu barang, dengan kode ini transaksi penjualan dapat berjalan dengan cepat dibandingkan dengan cara manual, akan tetapi selain Bar-Code ada lagi informasi yang dapat diperoleh dari QR-Code sebagai pemberi informasi alamat website. Akan tetapi banyak konsumen tidak bisa memanfaatkan informasi yang ada pada kode-kode tersebut. Dengan begitu informasi yang penting seperti alamat website jadi terbuang, padahal di dalam alamat website terdapat banyak sekali informasi yang diberikan agar para konsumen dapat lebih mengenal produk tersebut. Ada beberapa toko yang kesulitan dalam melakukan promosi, jika menggunakan brosur / pamflet dengan menggunakan kertas akan dibutuhkan biaya yang tidak sedikit, jadi sekarang banyak toko yang beralih menanfatkan ecommerce, akan tetapi para pemilik toko kesulitan dalam memanfaatkan media yang dapat berinteraksi dengan dengan pelanggan melalui internet.
Oleh karena itu diperlukan aplikasi yang dapat membaca QR-Code agar pemilik toko dapat menyampaikan promo pruduk atau diskon dari toko dengan cepat dan mudah, dengan memanfaatkan QR-Code pelanggan hanya memerlukan kamera handphone untuk membaca informasi yang terdapat pada QR-Code dan dengan bantuan aplikasi yang harus diinstal sebelumnya maka pelanggan dapat mengakses alamat website toko yang tercatat dalam database sehingga pelanggan mendapatkan informasi tentang promo dan pruduk-produk yang di tawarkan oleh pemilik toko dengan cepat dan mudah.

\section{TINJAUAN PUSTAKA}

Promosi merupakan salah satu cara untuk meningkatkan penjualan dari suatu toko atau perusahaan, tanpa melakukan promosi pelanggan tidak akan mengetahui produk-produk yang dijual, oleh karena itu penentuan media promosi yang tepat harus dipikirkan oleh pemilik toko [1] yang dapat ditinjau dari segi biaya dan cakupan wilayah promosi, media promosi yang menarik pelanggan salah satunya adalah media promosi melalui video profil, dimana promosi ini menunjukkan secara audio visual seputar produk yang dapat mereka beli, dengan media ini pelanggan dapat membayangkan bentuk produk walaupun tidak melihat secara langsung barang yang dijual [2], akan tetapi media ini proses distribusinya diperlukan waktu dan biaya yang cukup mahal.

Media promosi yang sangat berpengaruh pada konsumen adalah melalui televisi, dimana melalui media ini lingkup area promosi sangat luas 
dengan jumlah pelanggan yang menyaksikan promosi juga sangat banyak, melalui media ini pelanggan secara tidak sengaja dipaksa untuk melihat iklan misalnya iklan yang ditayangkan pada acara film penonton akan menunggu dan melihat iklan sampai selesai karena mereka menunggu tayangan film dilanjutkan, sehingga secara tidak langgsung penonton akan teringat selamanya produk yang ditayangkan di telivisi [3,4,5], akan tetapi media promosi melalui televisi membutuhkan biaya yang sangat tinggi, sehingga hanya perusahaan besar saja yang sanggup memanfaatkan media promosi ini.

Salah satu alternative promosi adalah memanfaatkan media internet, dimana melalui media ini ruang lingkup promosi menjadi tidak terbatas dan biaya promosi yang realtif murah $[6,7]$, akan tetapi kekurangan dari media promosi melalui internet adalah tidak semua toko atau perusahaan mampu membangun sistem promosi ini, karena dibutuhkan keahlian khusus untuk membangun media promosi melaui internet.

Salah satu perkembangan teknologi saat ini adalah QR-Code yang pertama kali diciptakan di Jepang untuk mengembangkan Bar-Code yang merupakan kode satu dimensi dan dikembangkan menjadi kode dua dimensi sehingga dapat menampung data yang lebih besar, sehingga dapat diimplementasikan di berbagi bidang diantaranya QR-Code untuk sistem presensi [8], pengelolaan distribusi kantong darah [9], pendaftaran mahasiswa baru [10], proses legalisari ijazh [11] dan banyak lagi aplikasi yang lain.

Dengan semakin banyaknya pelanggan yang menggunakan handphone maka akan lebih baik kalau dikembangkan aplikasi hanphone yang memanfaatkan QR-Code [12,13,14], dengan mengembangkan aplikasi handphone dapat dibangun suatu sistem promosi toko berbasis android yang memanfaatkan QR-Code sebagai trigger mendapatkan informasi promosi prduk barang atau diskon untuk meningkatkan penjualan pada toko.

\section{1. $Q R$ Code}

Qr code merupakan teknik yang mengubah data tertulis menjadi kode-kode 2 dimensi yang tercetak kedalam suatu media yang lebih ringkas. $Q r$ code adalah barcode 2 dimensi yang diperkenalkan pertama kali oleh perusahaan Jepang Denso Wave pada tahun 1994. Barcode ini pertama kali digunakan untuk pendataan inventaris produksi suku cadang kendaraan dan sekrang sudah digunakan dalam berbagai bidang. Qr adalah singkatan dari Quick Response karena ditujikan untuk diterjemahkan isinya dengan cepat. $Q R$-Code salah satu tipe dari barcode yang dapat dibaca dengan kamera handphone. (Rouillard, 2008).

Qr-Code mampu menyimpan semua jenis data, seperti data angka/numerik, alphnumerik, biner, kanji/kana. Selain itu Qr-Code mampu menampung data secara horizontal dan vertikal, jadi secara otomatis ukuran dari tampilan gambar $Q R$ Code bisa hanya persepuluh dari ukuran sebuah barcode. Tiga tanda bebentuk persegi di tiga sudut memiliki fungsi agar simbol dapat dibaca dengan hasil yang sama dari sudut manapun. (Wave, 2010).

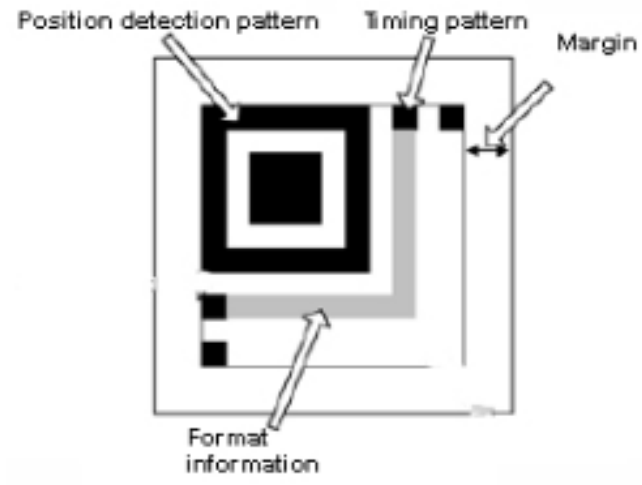

Gambar 1 Detail QR-Code

a) Position detection patterns: Posisi pola deteksi diatur pada tiga sudut kode QR. Posisi dari kode QR terdeteksi dengan pola deteksi posisi yang memungkinkan kecepatan tinggi membaca dan dapat dibaca dari segala arah.

b) Margin: Ini adalah area kosong di sekitar kode QR dan membutuhkan margin sebesar empat modul.

c) Timing pattern: Module putih dan modul hitam diatur secara bergantian untuk menentukan koordinat. Pola waktu ditempatkan diantara dua pola deteksi posisi dalam kode QR.

d) Format information: Informasi format dibaca pertama ketika kode tersebut diterjemahkan.

\subsection{Koreksi Kesalahan pada Qr Code}

QR Code memeiliki kemampuan mengoreksi kesalahan untuk mengembalikan data jika kode kotor atau rusak. Empat tingkat kesalahan koreksi yang tersedia bagi pengguna, tingkat ini mampu mengoreksi kesalahan pada. Faktor lingkungan dan ukuran $Q R$ Code perlu dipertimbangkan untuk menghitung tingkat kesalahan. Tingkat $\mathrm{Q}$ atau $\mathrm{H}$ dapat dipilih jika kondisi lingkungan kotor yang akan menyebabkan $Q R$ Code mengalami kerusakan, sedangkan tingkat $\mathrm{L}$ dapat dipilih jika kondisi lingkungan lebih bersih dengan jumlah data yang besar. Tingkat $\mathrm{M}$ adalah tingkat yang paling sering digunakan. Berikut tabel koreksi kesalahan $Q R$ Code.

\section{Table 1 Koreksi Kesalahan pada QR-Code}

\begin{tabular}{|l|l|}
\hline \multicolumn{2}{|l|}{ Kapasitas koreksi kesalahan OR-Code } \\
\hline Level L & Dapat mengkoreksi kesalan sampai 7\% \\
\hline Level M & Dapat mengkoreksi kesalan sampai 15\% \\
\hline Level Q & Dapat mengkoreksi kesalan sampai 25\% \\
\hline Level H & Dapat mengkoreksi kesalan sampai 30\% \\
\hline
\end{tabular}




\section{DESAIN SISTEM}

Desain sistem pada aplikasi Aplikasi Qr-Code memberitahukan apakah Qr-Code sudah terdafatar atau belum pada database yang akan di tunjukkan pada gambar 2 .
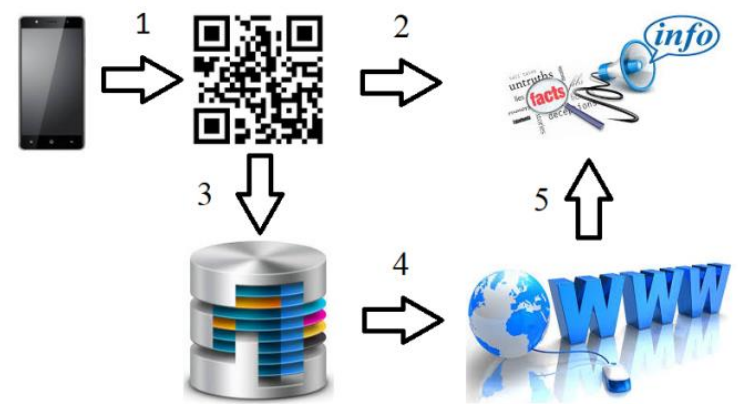

Gambar 2 Diagram Blok.

1. Android melakukan scanner pada Qr-Code.

2. Qr-Code yang belum terdaftar akan menampilkan informasi berupa terjemahaan dari qr code.

3. Qr-Code yang sudah terdaftar akan dicari datanya di dalam database.

4. Qr-Code yang terdaftar akan menampilkan website yang berisi informasi promo.

5. Setelah layar website ditutup akan menampilkan terjemahan dari kode Qr-Code.

\subsection{Arsitektur Informasi}

Arsitektur informasi pada sistem aplikasi QrCode akan di tunjukkan pada gambar 3 .

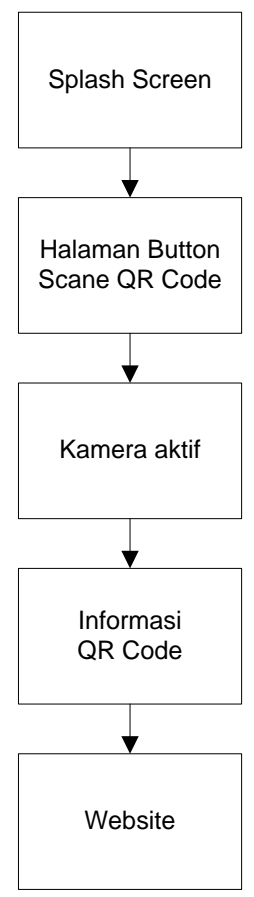

Gambar 3.2 Arsitektur informasi
Keterangan :

1. Splash Screen : tampilan awal saat membuka aplikasi

2. Button Qr-Code: tombol untuk meng aktifkan kamera

3. Kamera : berfungsi untuk melakukan scanner kode qr code

4. Informasi : menampilkan terjemahan dari kode qr code

5. Website : berisi informasi promosi

\subsection{Flowchart}

Untuk memperjelas proses-proses yang terjadi pada aplikasi maka akan ditunjukkan pada gambar 4 .

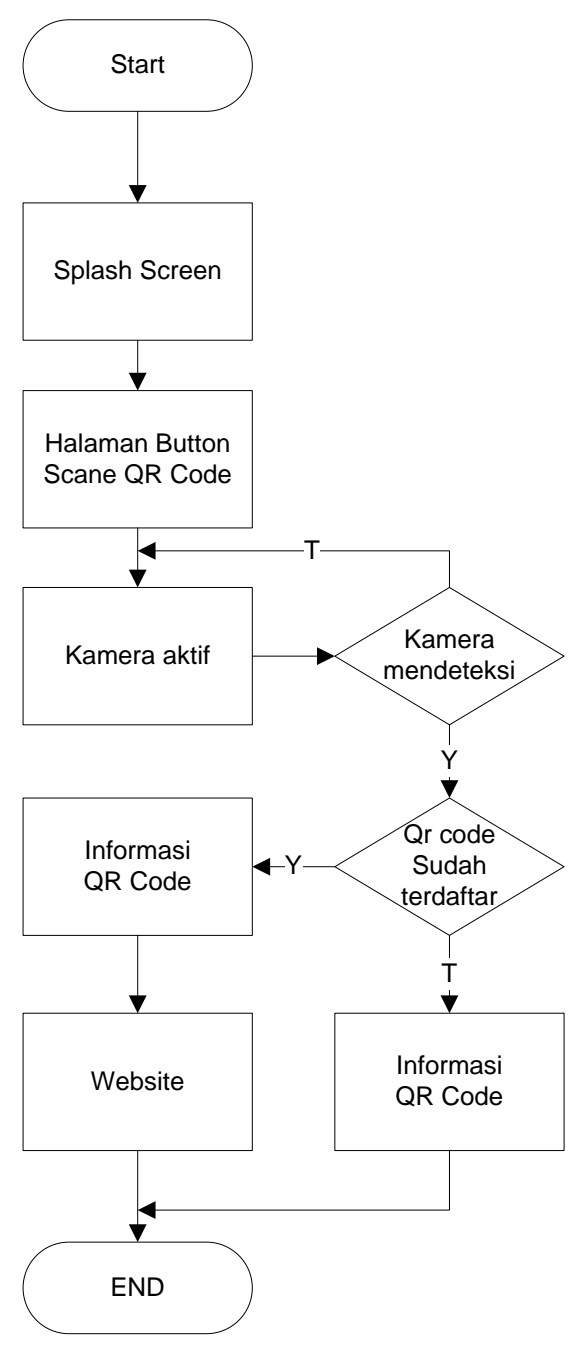

Gambar 4 Flowchart aplikasi

\section{Implementasi}

Implementasi dilakukan untuk menerapkan perancangan yang telah dilakukan terhadap sistem yaitu dengan membuat halaman home dari toko online dimana mencakup barang-barang yang dijual pada toko tersebut. 
Untuk mengetahui deskripsi dari setiap barang yang dijual pelanggan dapat memilih barang dengan cara click pada gambar produk yang ingin dibeli, setelah dipilih produknya maka akan masuk ke halaman deskripsi dari produk tersebut seperti gambar 5 dan 6 berikut

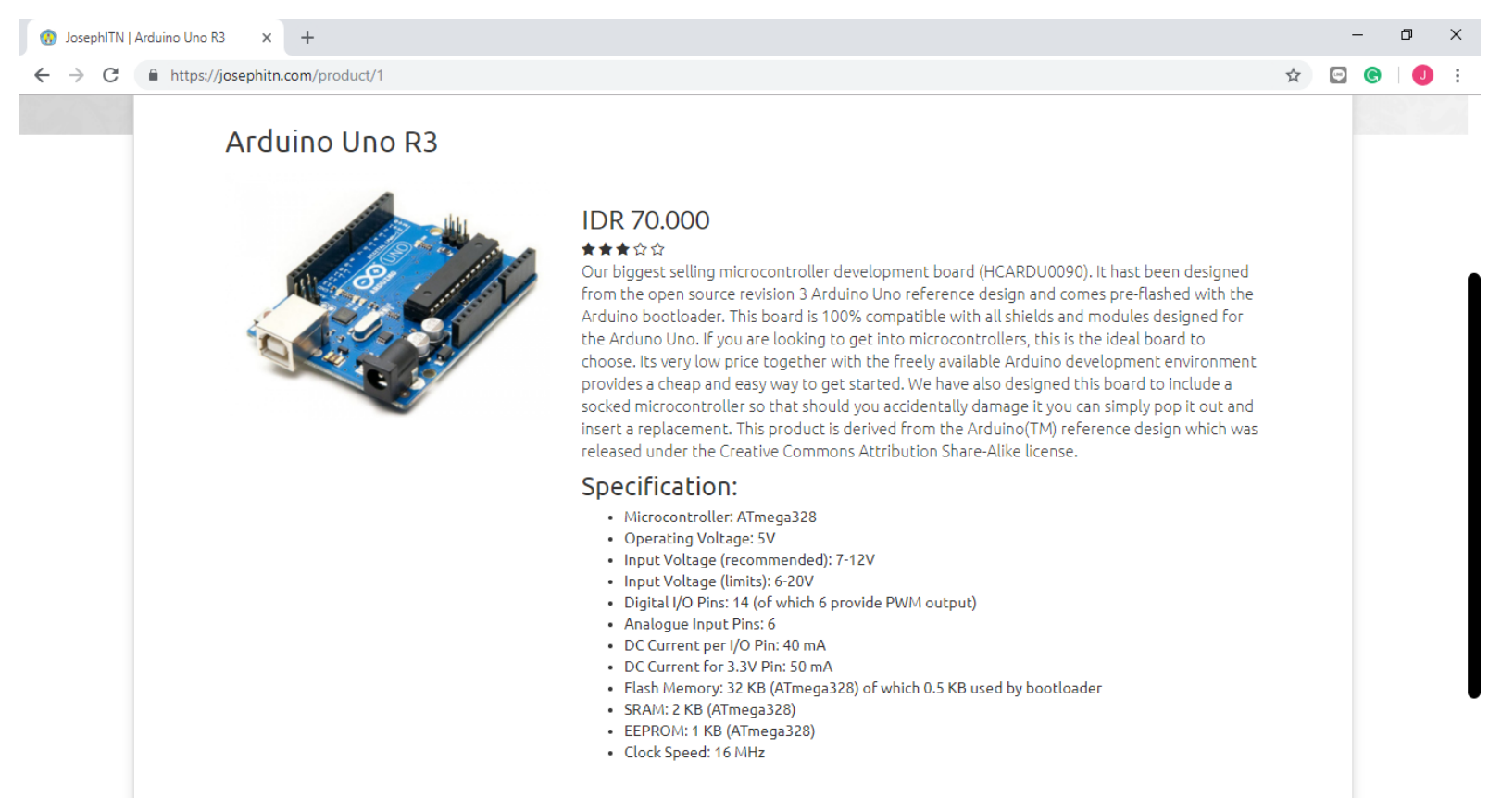

Gambar 5. Detail produk 1

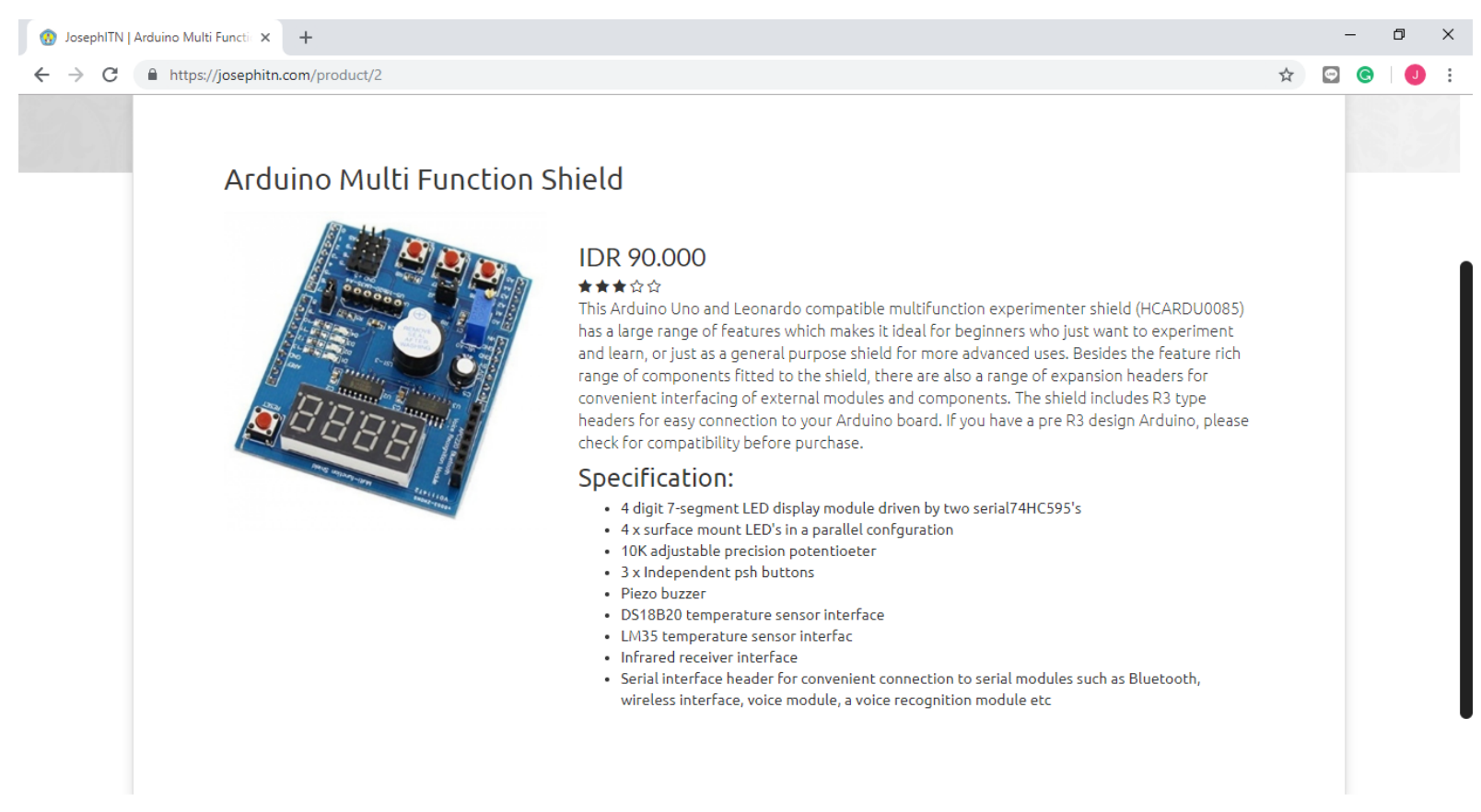

Gambar 6. Detail produk 2 

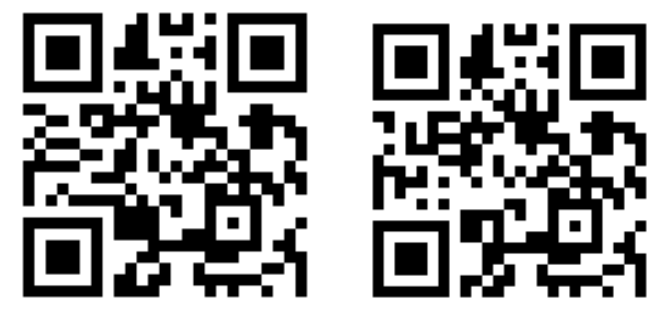

Gambar 7. QR-Code product 1 dan 2

Selain dengan cara menekan gambar produk di halaman web, penelusuran produk juga bisa dilakukan dengan menggunakan bantuan QR-Code pada gambar 7, dimana gambar tersebut merupakan link dari deskripsi product 1 dan 2, dengan cara melakukan scan dari QR-Code tersebut maka secara otomatis dapat menuju ke link dari produk yang sudah disiapkan di web penjual.

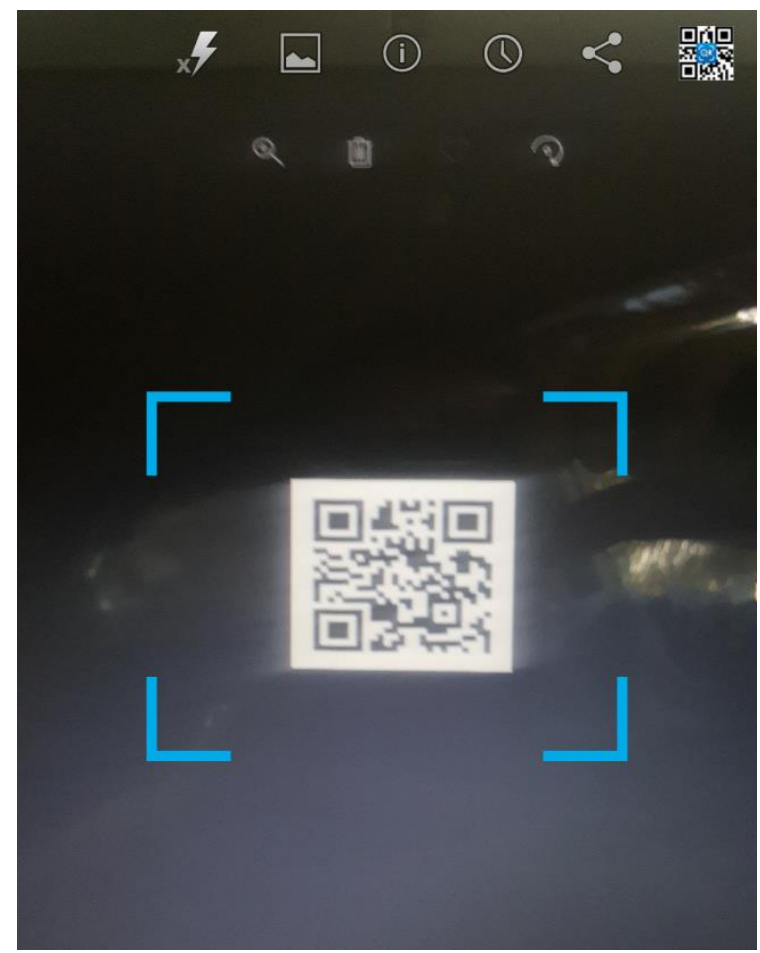

Gambar 8. Scan QE-Code menggunakan HP

OR-Code dapat dicetak dan dimuat pada brosur, web dan media-media lain untuk pemasaran, jika pembeli ingin mengetahui keterangan tentang produk tersebut cukup melakukan scan dari kode tersebut dan akan terhubung ke halaman web dari toko.

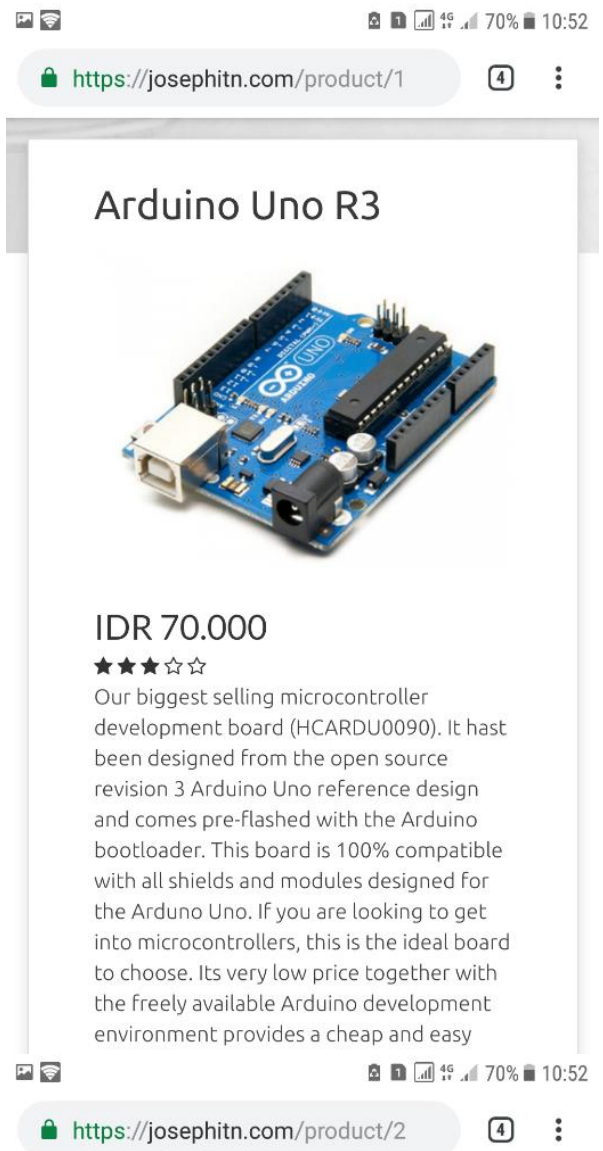

Arduino Multi

Function Shield

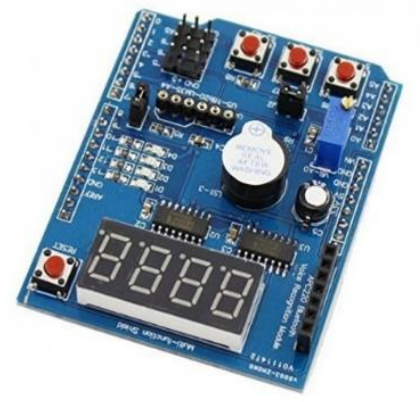

IDR 90.000

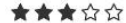

This Arduino Uno and Leonardo compatible multifunction experimenter shield (HCARDU0085) has a large range of

features which makes it ideal for beginners who just want to experiment and learn, or just as a general purpose shield for more advanced uses. Besides the feature rich range of components fitted to the shield,

Gambar 9. Ujicoba deskripsi produk menggunakan $\mathrm{HP}$ 
Proses pembacaan dari deskripsi barang dapat dilakukan menggunakan komputer maupun HP, sehingga menjadi lebih mudah dilakukan oleh pembeli.

\section{KESIMPULAN DAN SARAN}

\subsection{Kesimpulan}

Berdasarkan hasil analisis, perancangan, dan pengujian penulis mengambil kesimpulan dengan memanfaatkan QR-Code dalam promosi produk toko dapat menarik minat pembeli, karena dalam menampilkan deskrispsi produk menjadi lebih mudah dan cepat tanpa harus mengetikkan link dari web tentang diskripsi produk.

\subsection{Saran}

saran untuk pengembangan selanjutnya dari aplikasi QR-Code, antara lain:

Aplikasi memiliki tampilan yang lebih menarik lagi dan memiliki banyak fitur tambahan.

\section{DAFTAR PUSTAKA}

Novaliendry, D., 2009. Aplikasi Penggunaan Metode Promethee Dalam Sistem Pendukung Keputusan Untuk Penentuan Media Promosi Studi Kasus: STMIK Indonesia. Jurnal Ilmiah Kursor, 5(2).

Prastyo, N.A., 2012. Pembuatan Video Profil Tiga Dimensi (3D) Sentra Ponsel Kudus. SpeedSentra Penelitian Engineering dan Edukasi, 2(4).

Sugihartono, R.A., 2016. TELEVISI LOKAL SEBAGAI MEDIUM PENCITRAAN LOKALIAS DAERAH. Acintya, 1(1).

Arfianto, W. and SUTOPO, S., 2010. Analisis Faktor-Faktor Yang Mempengaruhi Efektivitas Iklan Pada Media Televisi (Studi Pada Iklan Produk Sepeda Motor Honda)

Sadariskar, A., 2006. Pengaruh terpaan iklan televisi terhadap tingkat afeksi: Studi kasus iklan produk susu bubuk Dancow bagi Ibu-ibu di RW 08, Kelurahan Kampung Melayu Jakarta Timur (Doctoral dissertation, FISIP-UI).

Indah, I.N. and Yulianto, L., 2012. Pembuatan Website Sebagai Sarana Promosi Produk
Kelompok Pidra Desa Gawang Kecamatan Kebonagung Kabupaten Pacitan. Speed-Sentra Penelitian Engineering dan Edukasi, 3(4).

Aryanto, A. and Tjendrowaseno, T.I., 2013. Pembangunan Sistem Penjualan Online Pada Toko Indah Jaya Furniture Surakarta. SpeedSentra Penelitian Engineering dan Edukasi, 4(4).

Muharom, L.A. and Sholeh, M.L., 2016. SMART PRESENSI MENGGUNAKAN QR-Code DENGAN ENKRIPSI VIGENERE CIPHER. Limits: Journal of Mathematics and Its Applications, 13(2), pp.31-44.

Nugraha, G., Setiani, N. and Setiaji, H., 2017, August. Pemanfaatan QR-Code Pada Pengelolaan Kantung Darah. Studi Kasus: PMI Sleman. In Seminar Nasional Informatika Medis (SNIMed) (pp. 55-59).

Gunawan, H., 2015. Pemanfaatan Teknologi QR Code Dalam Pengembangan Sistem Pendaftaran Calon Mahasiwa Baru di Universitas Islam Riau. JTT (Jurnal Teknologi Terapan), 1(1).

Hidayat, E.Y., Firdausillah, F. and Hastuti, K., 2015. SISTEM LEGALISIR SCAN IJASAH ONLINE BERBASIS QR CODE DAN WATERMARKING. Techno. Com, 14(1), pp.13-24.

Prasetia, A., 2017. APLIKASI BERBAGI KONTAK MENGGUNAKAN QR CODE UNTUK SMARTPHONE ANDROID. Prodi Teknik Informatika UPY.

Habibi, G., Purwantoro, S. and Akbar, M., 2012. Smart Poster Aplikasi Pemesanan Tiket Nonton Bioskop Berbasis Android. Jurnal Aksara Komputer Terapan, 1(1).

Wahyutama, F., Samopa, F. and Suryotrisongko, H., 2013. Penggunaan Teknologi Augmented Reality Berbasis Barcode sebagai Sarana Penyampaian Informasi Spesifikasi dan Harga Barang yang Interaktif Berbasis Android, Studi Kasus pada Toko Elektronik ABC Surabaya. Jurnal Teknik ITS, 2(3), pp.A481-A486 